\title{
A Study of Processing Parameters on the Carburization of C2R Steels
}

\author{
P.O. Atanda ${ }^{1}$, O.E. Olorunniwo ${ }^{1}$, L.E. Umoru ${ }^{1}$, and A.D. Adeyeye ${ }^{2}$ \\ ${ }^{1}$ Department of Materials Science and Engineering \\ Obafemi Awolowo University, Ile-Ife. Nigeria. \\ ${ }^{2}$ Department of Industrial Engineering, University of Ibadan. Nigeria \\ *Correspondence Author email: atandapo@oauife.edu.ng Phone:+2348033603709
}

\begin{abstract}
This study reports an investigation of the effect of carburizing variables - temperature, time and percentage of energizer -on the case properties of C2R steel obtained from HMT Ltd. India. A carburizer consisting of hardwood charcoal and coke respectively in the ratio of 2:1 was used for the research with sodium carbonate as the energizer. The carburizing box was filled with 20 $\mathrm{mm}$ thick carburizer compound prior to fixing the steel samples in place. The specimens were carburized using different percentages of energizers (10,20 and 30\%) at different temperatures (820, 860, 900 and $940^{\circ} \mathrm{C}$ ) for different times (from one to five hours). All the specimens were quenched from carburizing temperature, ground to polished surfaces and then etched for ten minutes in $25 \%$ Nital. The case depth was measured using the calibrated ocular of an inverted metallurgical microscope fixed at $100 \times$ magnification. The hardness values of the C2R steel cases were measured with a micro hardness tester that uses diamond pyramid indenter. The results of the study showed that the average hardness of the C2R steel cases increased with temperature for any given carburizing time and temperature. For a given percentage energizer and temperature, the case depths and hardness increased with time. Increase in the percentage energizer however decreased the activation energy required for diffusion to occur exponentially.
\end{abstract}

Keywords : Carburizer, Energizer, Heat treatment, Case depth, Activation Energy, Diffusion.

\section{INTRODUCTION}

The service conditions of many steel components such as gears, cams, valves etc, make it necessary for them to possess both hard and wear resistant surfaces but tough and shock resistant 
cores [1]. A low carbon steel of approximately $0.1 \%$ carbon will be tough while a high carbon steel of about $0.9 \%$ or more will possess adequate hardness (and inherently low toughness) when suitably heat-treated. The combination of hard, wear resistant surface and tough core required in the aforementioned components involves the treatment of a shock- resistant steel so as to alter the nature of the surface in order to increase the hardness while the core remains more or less unaltered.

There are two major processes through which such an alteration of the surface layers of steel components may be carried out, namely, (i) processes which impart surface hardness by changing the microstructure of the surface skin without changing the chemical composition of the surface. Such steel must not have a carbon content of less than $0.4 \%$ for them to be amenable to hardening (by any of flame, induction, laser, and electron beam hardening) (ii) processes which impact surface hardness by changing the surface chemistry of the steel by diffusing carbon, nitrogen or both carbon and nitrogen into its surface. Steels for this process may have a carbon content of about $0.1 \%$. Examples of this latter process include carburizing, nitriding, cyaniding, diffusion coating, and hard surfacing.

The method of carburizing was selected for this investigation because it has the advantages of ease of operation, adaptability and portability of the equipment required, ability to heat-treat component after surface- finishing (since there is little oxidation, decarburization or distortion), and the ease of producing deeper zones of case depth.

It is known that the inward diffusion of the carbon takes place at a rate which depends on the chemical composition of the steel, the carburizing temperature and the chemical composition of the carburizing mixture [2, 3]. Established is a concentration gradient in respect of carbon from the skin to the core of the steel. With increase in the carburizing activity of the carburizing compound, the concentration is made steeper; the depth of penetration is not however increased to the same extent.

In general, the case depth is controlled by the adjustment of the carburizing time and temperature. There is a limit to which temperature can be increased in case hardening. At high temperatures, the structure of the core deteriorates. It badly affects the diffusion too. At elevated temperature, the rate at which the diffusing element is deposited on the surface of the specimen is greater than the rate at which it diffuses towards the core of the steel. This leads to uneven distribution of the concentration of the element and a high concentration which may lead to the formation of networks of chemical compounds such as carbides and nitrides, which impacts high brittleness to the surface layer. The yield strength of the core of a carburized component may be exceeded, particularly as the core is in a state of tensile stress [4]. 
Although the stress is within the fatigue limit, the stress in the case is due both to the increased strength of the surface layer and to the development of favourable compressive residual stresses close to the surface.

For a successful carburization, a control of all these parameters; the carburizing temperature, carburizing time, and chemical composition of the carburizing compound must be effected $[5,6,9]$.

In this work, the effect of carburizing variables on C2R steel used in machine tool operation for the manufacture of different machine tool components has been studied with the aim of improving both the production processes and the manufactured components used in machine tools operation $[7,8]$. The components studied include gears of different shapes and contours, like the spiral, bevel, worm, taper, helical, etc.

\section{MATERIALS AND METHODS}

The composition of the $\mathrm{C} 2 \mathrm{R}$ steel used in this work is given in the Table 1 below. The carburizer was made in the ratio 2:1, hardwood charcoal and coke, with sodium carbonate $\left(\mathrm{Na}_{2} \mathrm{CO}_{3}\right)$ as energizer. The composition of carburizer used was shown in Table 2 below. The steel, C2R, is normally used for the manufacture of different kind of gears, shafts, worm-wheel, rack and pinion etc, in machine tool building. A 22.0mm diameter cylindrical specimen was used in order to avoid "edge" effect during carburizing. Clay was used to lute the lid of the carburizing container.

Table 1. Chemical composition of C2R steel (Diameter of specimen=22mm, Hardness= 240(HB)

\begin{tabular}{|l|l|l|l|l|l|l|l|l|}
\hline $\mathrm{C}(\%)$ & $\mathrm{Si}(\%)$ & $\mathrm{Mn}(\%)$ & $\mathrm{P}(\%)$ & $\mathrm{S}(\%)$ & $\mathrm{Cu}(\%)$ & $\mathrm{Cr}(\%)$ & $\mathrm{Ni}(\%)$ & $\mathrm{Sn}(\%)$ \\
\hline 0.15 & 0.23 & 0.50 & 0.040 & 0.040 & 0.025 & 0.10 & 0.011 & 0.05 \\
\hline
\end{tabular}

The box was first filled with the carburizer compound about 20mm thick which was then rammed and the components were placed about $25 \mathrm{~mm}$ away from the sides of the carburizing box. A digital chemical balance was used to weigh the generator (63\% charcoal and $37 \%$ of coke) and the energizer $\left(\mathrm{Na}_{2} \mathrm{CO}_{3}\right.$ in the ratios 9:1, 8:2, and 7:3. A cylindrical steel container (diameter $60 \mathrm{~mm}$ ) was used to contain the carburizer and the specimen. Carburizing was done in a heat-treatment furnace (electrically energized).

Grinding machine and rotary polishing machine were used to prepare the specimen for case depth measurement. A metallurgical microscope with calibrated ocular was used to measure the case depth and microhardness tester (diamond pyramid) to measure the hardness of the case. 
The generator (63\% charcoal and $37 \%$ coke) and energizer $\left(\mathrm{Na}_{2} \mathrm{CO}_{3}\right)$ were weighed respectively according to the formulation in Table 2. The specimens were packed with the carburizer in the carburizing container making sure that the specimen was covered with about $20 \mathrm{~mm}$ of carburizer. The lid was coated with clay and placed in the furnace.

The specimens were carburized at different temperatures $\left(820,860,900\right.$ and $\left.940^{\circ} \mathrm{C}\right)$, for different lengths of time (from one to five hours) and different percentages of energizers (10,20 and 30). All the specimens were quenched from the carburizing temperature, sectioned, ground and polished. The specimens were etched with $25 \%$ Nital $\left(25 \% \mathrm{HNO}_{3}\right.$ and $75 \%$ ethyl alcohol) for about ten minutes. Case depth was measured with micrometer screw gauge and hand lens. The hardness of the case was measured with microhardness tester using diamond pyramid indenter.

Table 2. Composition of carburizer.

\begin{tabular}{|l|l|}
\hline Generator (wt\%) & Energizer (wt\%) \\
\hline 90 & 10 \\
80 & 20 \\
70 & 30 \\
\hline
\end{tabular}

\section{RESULTS AND DISCUSSION}

In order to analyze the results of this investigation, particularly as regards the effect of the carburizing variables on the depth and hardness of C2R steel cases, graphs of Figs. 1 to 13 have been used to summarize pictorially the effects of the investigated variables. Also, plates $1 \mathrm{a}, 1 \mathrm{~b}$, $2 \mathrm{a}$ and $2 \mathrm{~b}$ are included to reveal the effects of carburizing time, temperature and proportion of carburizing energizer, $\mathrm{Na}_{2} \mathrm{CO}_{3}$ on case depth microstructures.

It is clear from Figs. 1-3 that the case depth increases with increase in carburizing time and temperature. Significantly, the three figures show that $820^{\circ} \mathrm{C}$ should not be considered as a carburizing temperature for $\mathrm{C} 2 \mathrm{R}$ steel because of its case depth that was relatively low even up to higher carburizing times. Temperatures $860^{\circ} \mathrm{C}$ and $900^{\circ} \mathrm{C}$ for carburizing exhibited similar features in terms of their slopes, an indication that they have comparable activation energies [3, 10]. For all the three energizer compositions investigated, the graphs show that $940^{\circ} \mathrm{C}$ stands out as an effective carburizing temperature.

Figures 4, 5 and 6 show that carburizing time almost exhibited linear relationship with case depth. Generally, the depth of the cases also increased with carburizing time and temperature.

The effect of energizer's proportion on case depth is contained in Figs. 7 and 8 . It can be seen that for any given carburizing time and temperature case depth increases as the percentage energizer increases. This is probably so because increase in energizer composition increases the nascent carbon on the surface of the steel. In other words, there would have been an increase in 
the carbon potential of the carburizer and consequently a higher diffusion rate of carbon into steel leading to an increased case depth as the percentage of the energizer $\left(\mathrm{Na}_{2} \mathrm{CO}_{3}\right)$ increases.

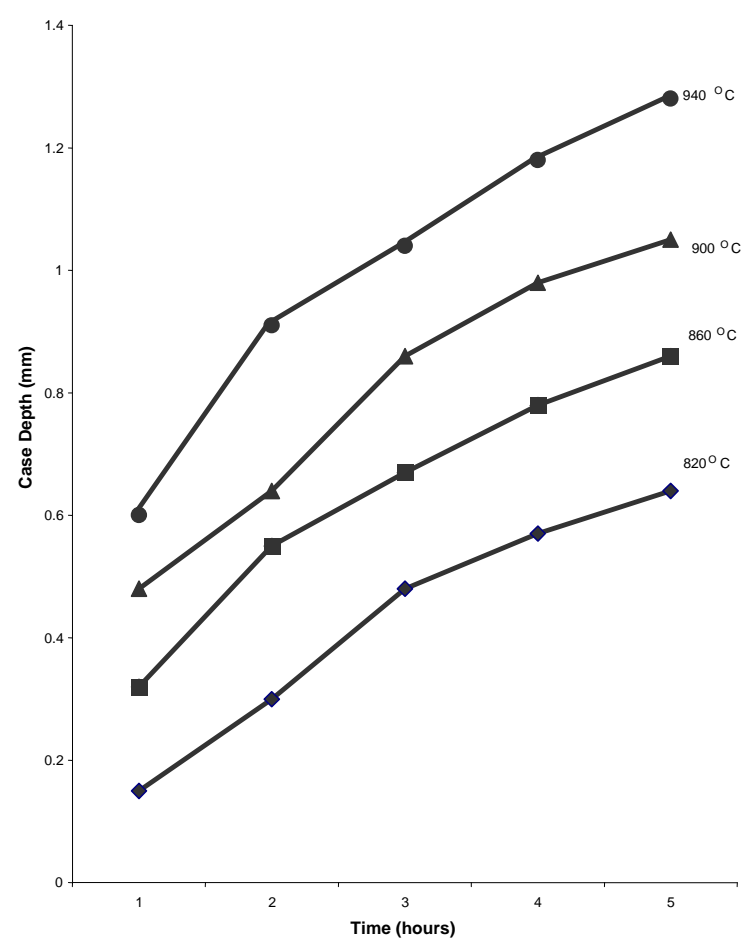

Fig. 1. The Relationship between Case depth (mm) and temperature for different carburizing time using $10 \%$ Na2CO3 (as quenched).

It can also be found in the figures earlier referred to that for any given carburizing temperature and time the hardness of the case increases with the percentage of energizer used in the carburizer. This is so because higher proportion of energizer implies an increase in carbon potential and hence more carbon would have diffused into the steel than when lower percentage of energizer was used.

An increase in carbon content in the case lead to an increase in its hardenability on quenching and since there is more carbon in the case with high percentage of energizer, the case would be harder.

The effects of carburizing temperature and time on the hardness of case are shown in Figs 9, 10 and 11. The average hardness of the case increases with temperature for any given carburizing time and percentage energizer. The explanation for this is that temperature increase diffusion rate, leading to a case of higher carbon content than a case developed at a lower temperature. This leads to the formation of more martensite on quenching and hence increased hardness. The increase of solubility of carbon in austenite with temperature is another factor. 
84

P.O. Atanda, O.E. Olorunniwo, L.E. Umoru, and A.D. Adeyeye

Vol.8, No.2

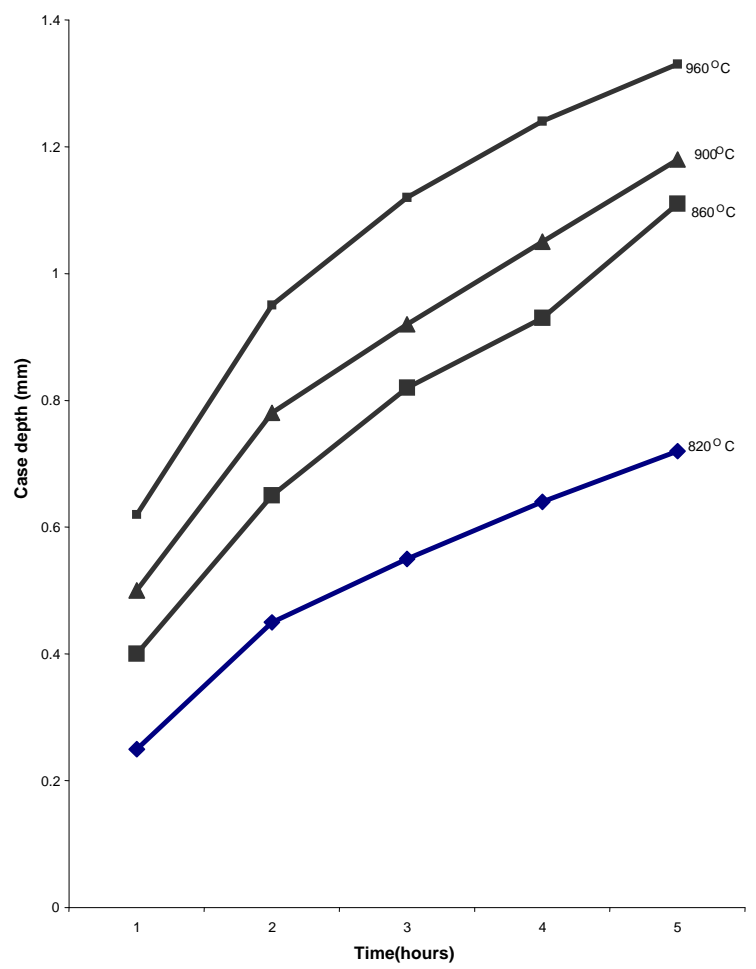

Fig 2 The relationship between case depth $(\mathrm{mm})$ and temperature for different carburizing time using $20 \% \mathrm{Na}_{2} \mathrm{CO}_{3}$ (as quenched)

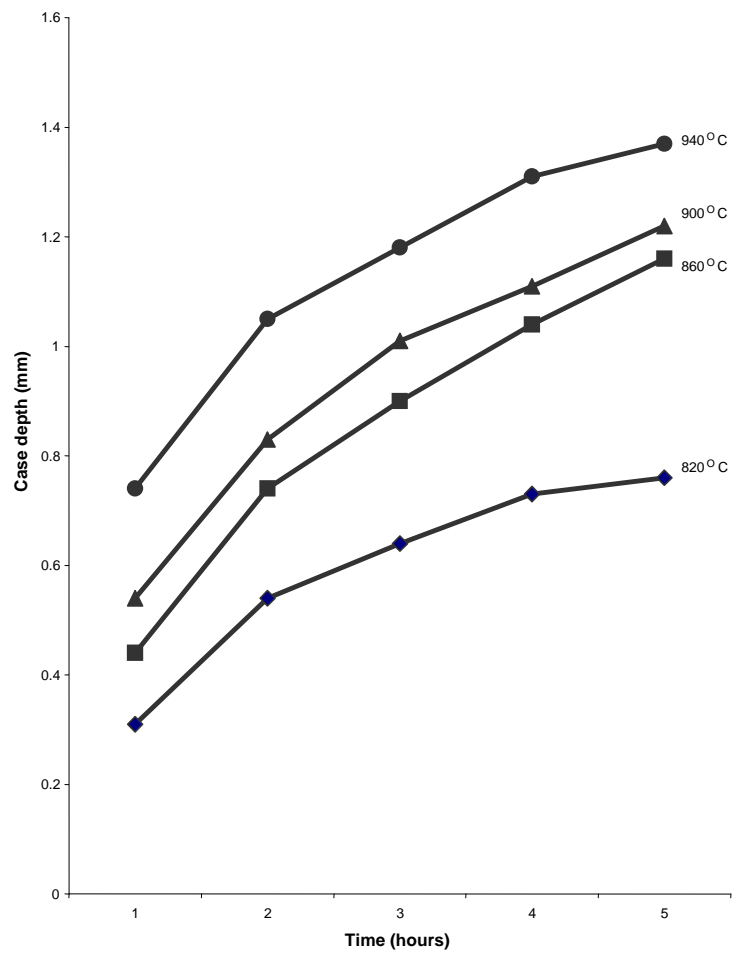

Fig 3The relationship between case depth $(\mathrm{mm})$ and temperature for different carburizing time using $30 \% \mathrm{Na}{ }_{2} \mathrm{CO}_{3}$ (as quenched) 


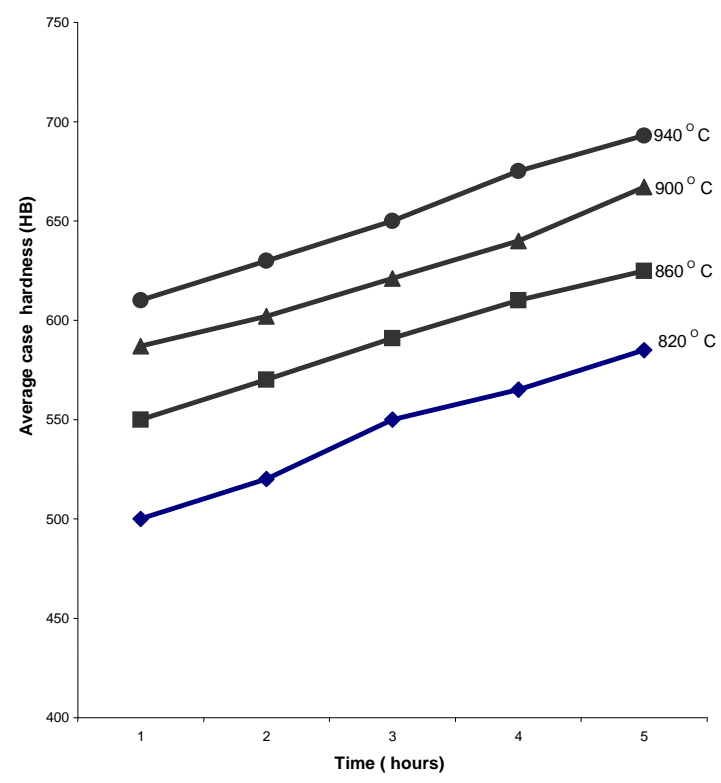

Fig 4 The relationship between average case hardness(HB) and carburizing time at various temperatures using $10 \% \mathrm{Na}_{2} \mathrm{CO}_{3}$

$$
\text { (as quenched) }
$$

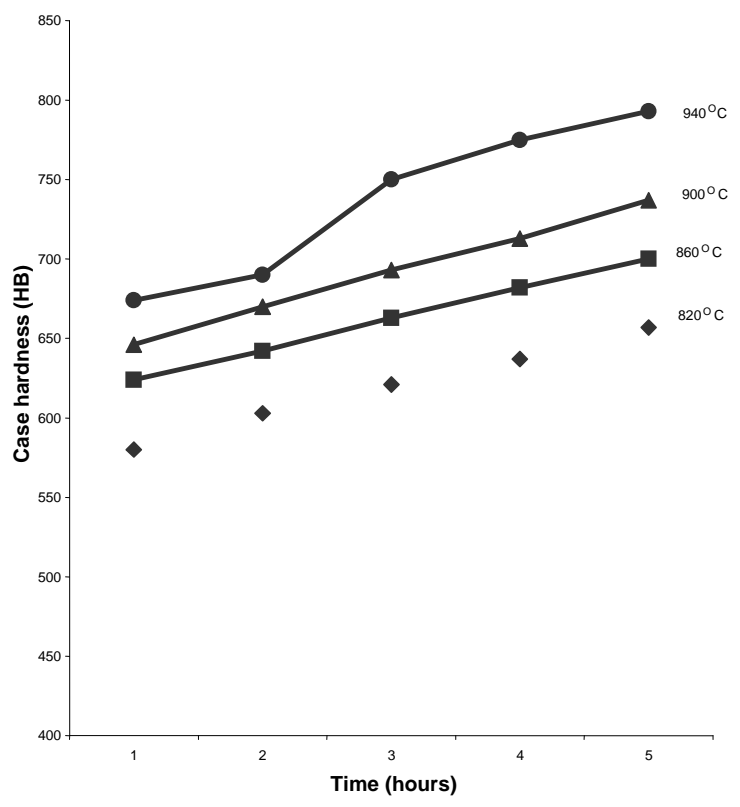

Fig 5 The relationship between average cas and carburizing time at various temperatures using $20 \% \mathrm{Na}_{2} \mathrm{CO}_{3}$ (as quenched) 


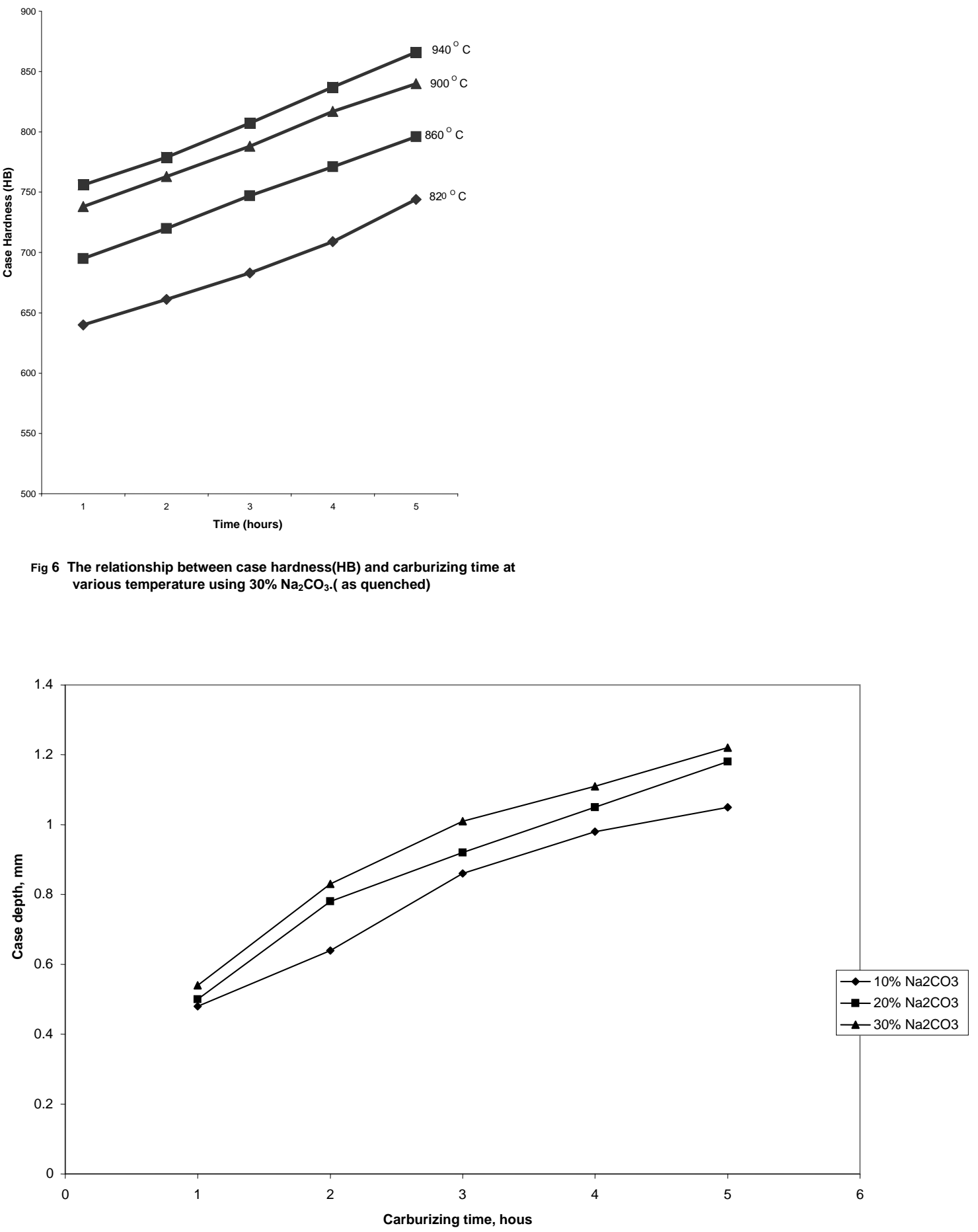

Fig. 7 The relationship between case depth and proportion of energizer $\left(\mathrm{Na}_{2} \mathrm{CO}_{3}\right)$ at carburizing temperature of $900^{\circ} \mathrm{C}$ 


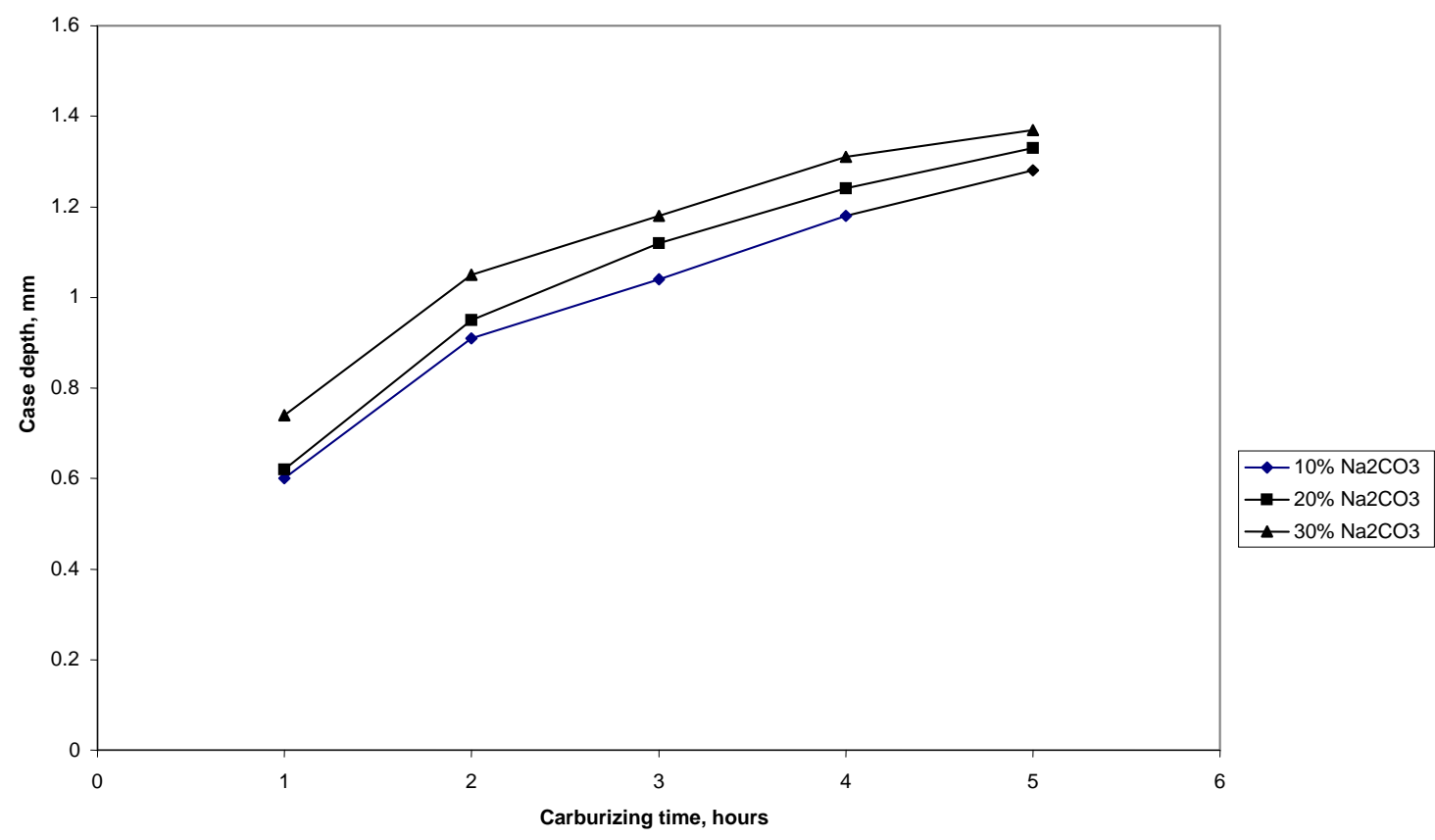

Fig 8 The relationship between case depth and proportion of energizer $\left(\mathrm{Na}_{2} \mathrm{CO}_{3}\right)$ at carburizing temperature of $940^{\circ} \mathrm{C}$

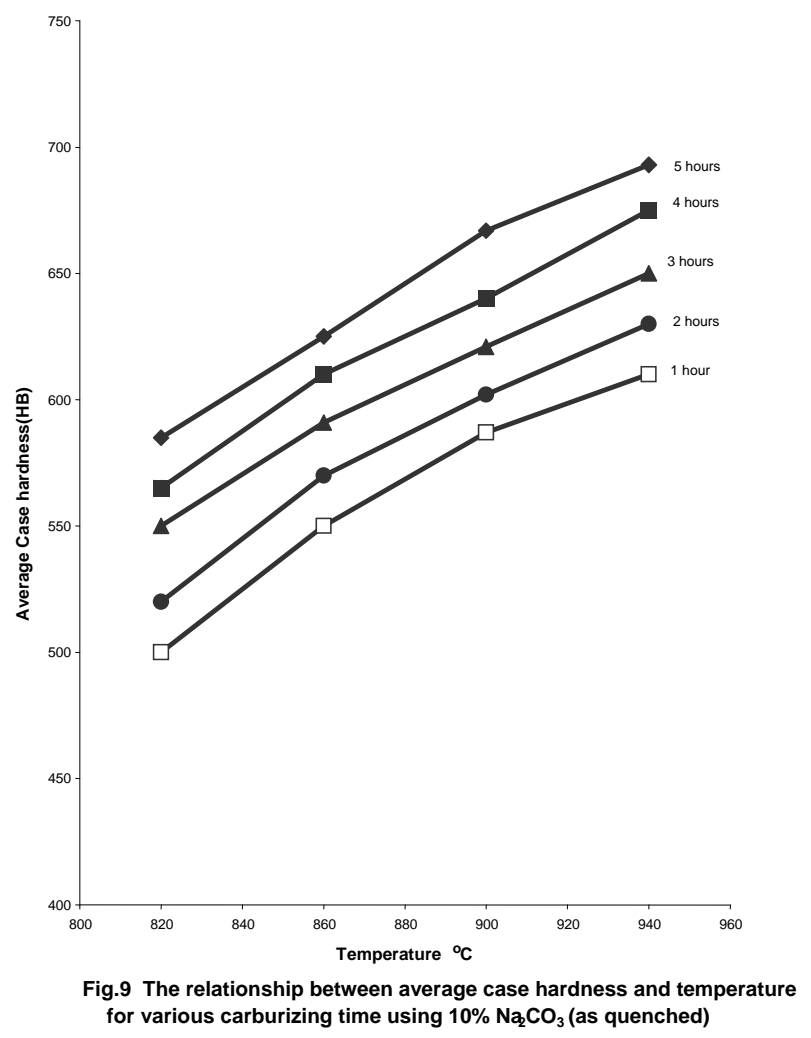




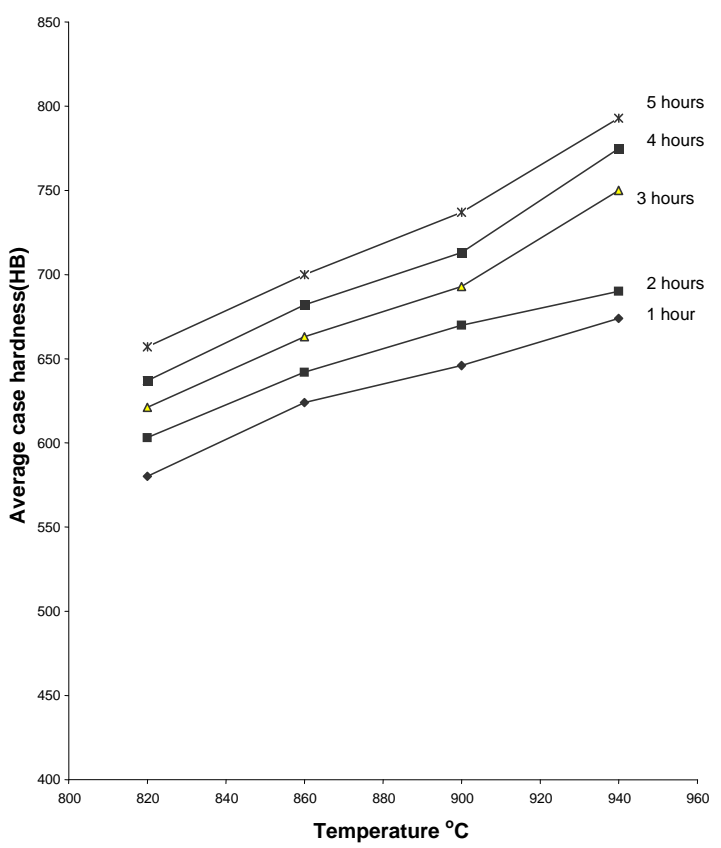

Fig.10 The relationship between average case hardness and temperature for various carburizing time for $20 \% \mathrm{Na}_{2} \mathrm{CO}_{3}$ (as quenched)

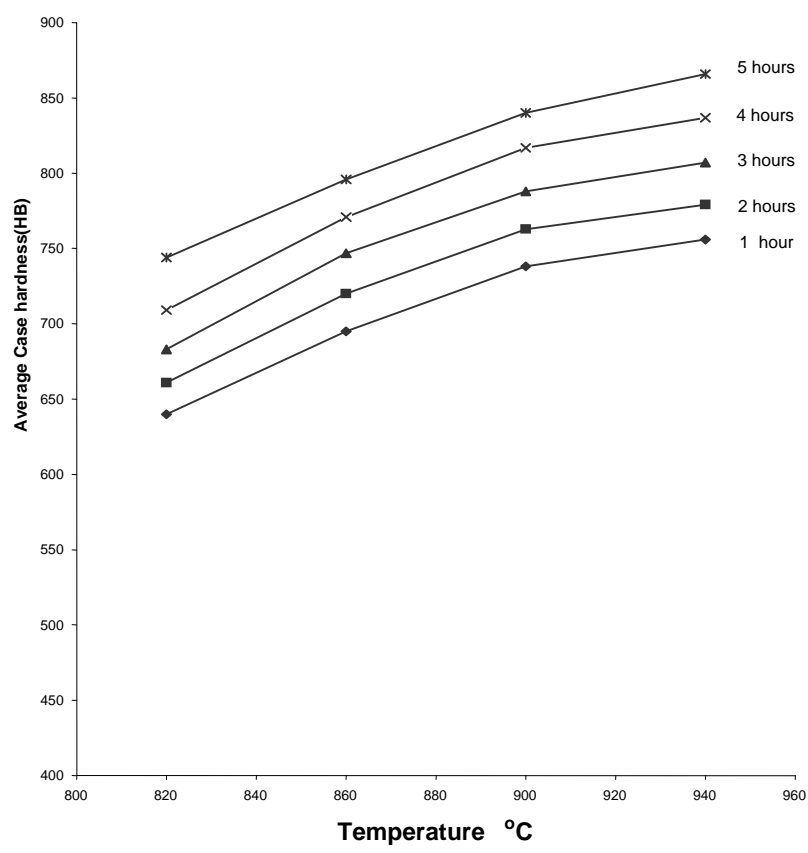

Fig.11 The relationship between case hardness and temperature for different carburizing time using $30 \% \mathrm{Na}_{2} \mathrm{CO}_{3}$ (as quenched)) 


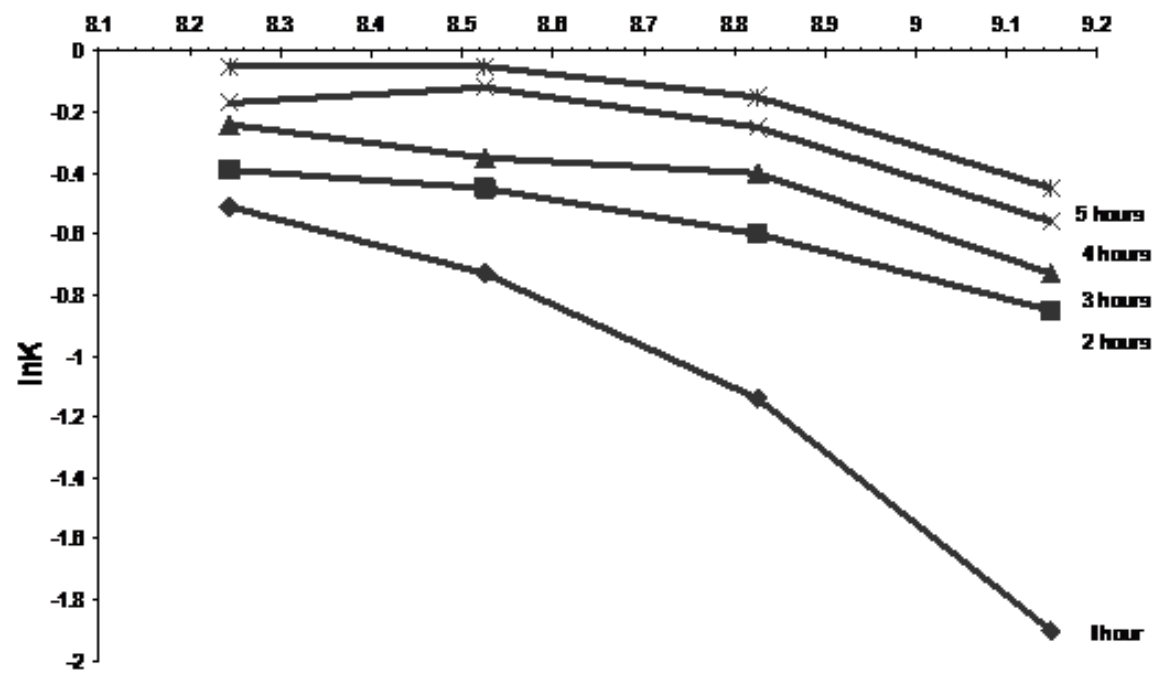

VT $110+K\}$

Fig 12 : The variation of linK with $\mathrm{I} / \mathrm{T}$ for various carburizing time using $10 \% \mathrm{Na}_{2} \mathrm{CO}_{3}$ (Energizer) as quenched.

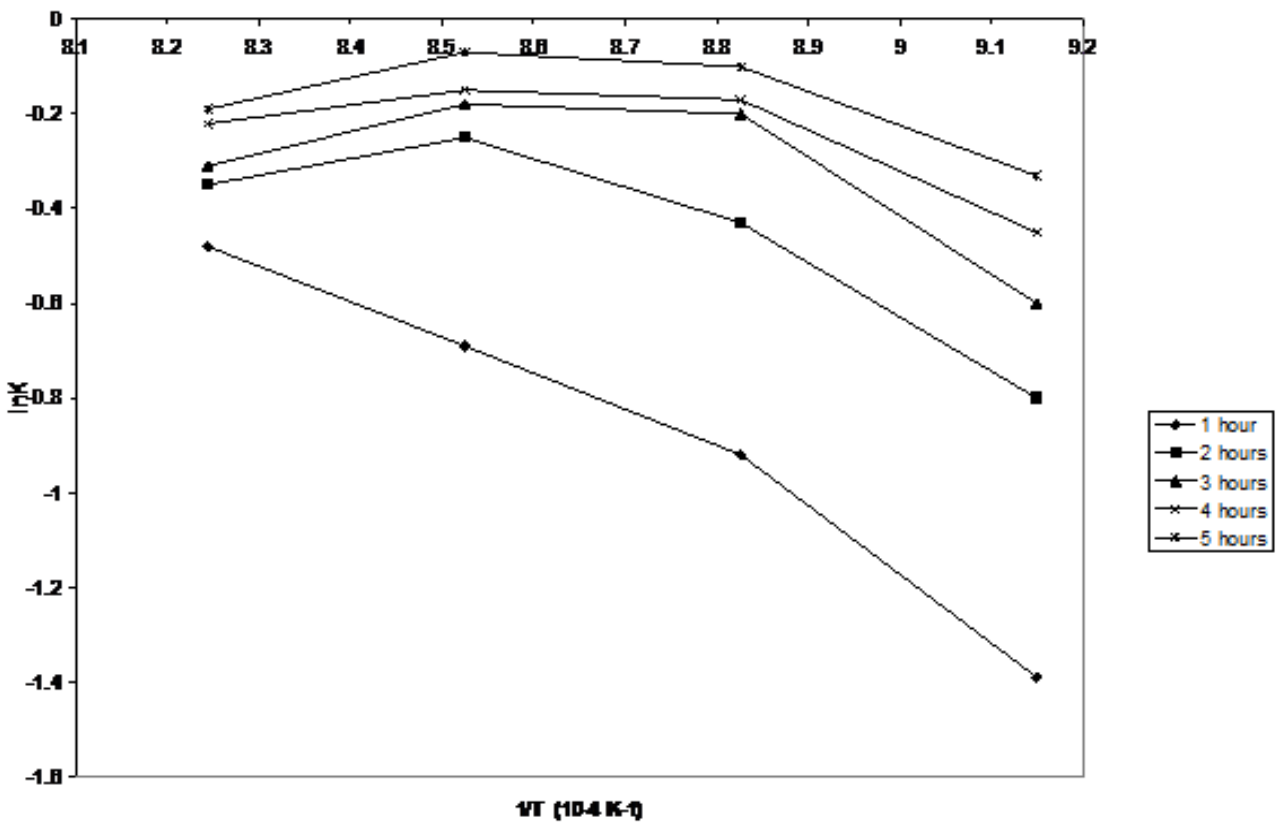

Fig 13. The variation of linK with $\mathrm{I} / \mathrm{T}$ for various carburizing time using $20 \% \mathrm{Na}_{2} \mathrm{CO}_{3}$ (Energizer) as quenched. 


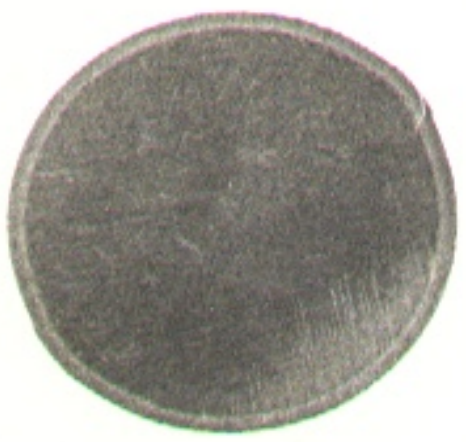

Plate 1(a)

Macrostructure of a specimen, carburized at $940^{\circ} \mathrm{C}$ for 3 hours The carburizer contained 20\% $\mathrm{Na}_{2} \mathrm{CO}_{3}$ Etched in 25\% Nital.

Magnification : x 2

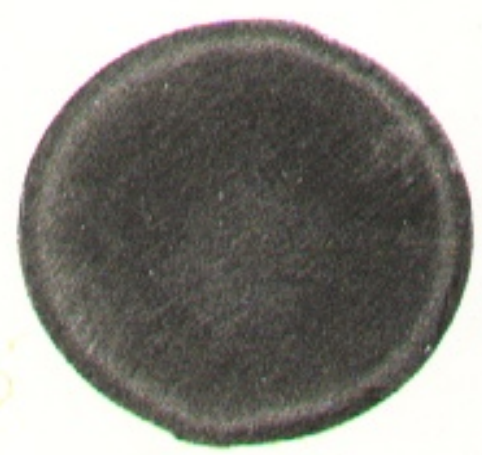

Plate 1(b)

Macrostructure of a specimen, carburized at $940^{\circ} \mathrm{C}$ for 4 hours The carburizer contained 20\% $\mathrm{Na}_{2} \mathrm{CO}_{3}$ Etched in $25 \%$ Nital. $\mathrm{x} 2$ Magnification : x2

Plates 1(a)and 1(b) show the effect of carburizing time on the case depth. The ring shape layer in the case The inner ring is the transition zone where the carbon content of the case decreases gradually into the carbon content of the case .

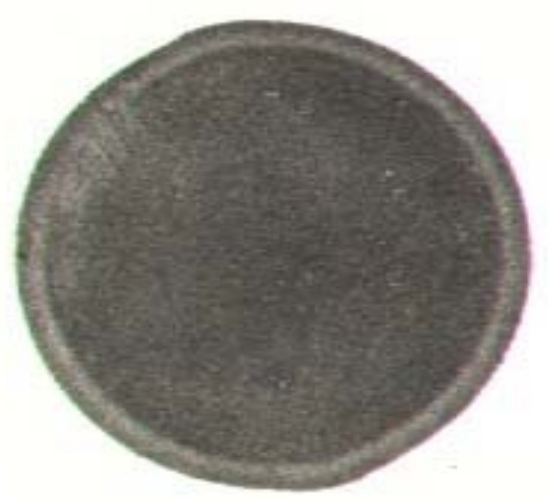

Plate 2 (a)

Macrostructure of a specimen, carburized at $900^{\circ} \mathrm{C}$ for 3 hours The carburizer contained 20\% $\mathrm{Na}_{2} \mathrm{CO}_{3}$ Etched in $25 \%$ Nital. Magnification: x2

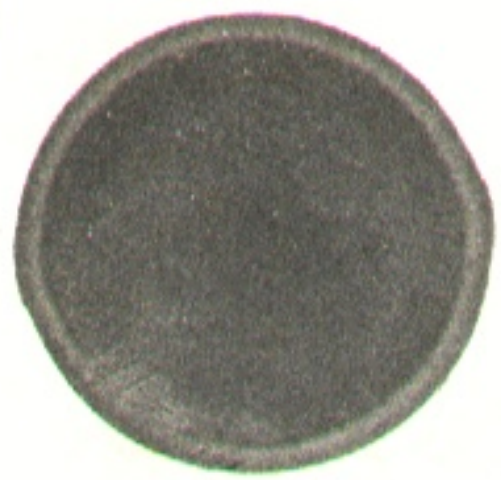

Plate 2 (b)

Macrostructure of a specimen, carburized at $900^{\circ} \mathrm{C}$ for 3 hours The carburizer contained $20 \%$ $\mathrm{Na}_{2} \mathrm{CO}_{3}$ Etched in $25 \%$ Nital. $\mathrm{x} 2$ Magnification : x2

Plates 2(a)and 2(b) show the effect of temperature on case depth. The ring shape layer is the case. The inner ring is the transition zone where the carbon content if the case decreases gradually into the carbon content of the core. 
The effect of the carburizing variables on the activation energy of the process is contained in Figs. 12 and 13. The two figures show that for any given carburizing time, the activation energy decreases as percentage energizer increases. The shape of the curves suggests that the rate of change of activation energy with percentage energizer is instantaneous. Since increase in energizer concentration increases the carbon potential (i.e. increases the $\mathrm{CO}$ to $\mathrm{CO}_{2}$ ratio) $[2,6]$, it implies that the number of carbon atoms at the surface of the steel will also be increased leading to a decrease in the activation energy. In addition the number of atoms that possess enough energy to diffuse also increases. Also obvious from these figures is the fact that activation energy decreases as time increases. The relation is an exponential one and the rate of change of activation energy with time is instantaneous. Decrease in activation energy is higher at shorter period than longer period.

The decrease in activation energy with increase in time may be due to increase in carbon concentration in the surface layer. However, decrease in the rate of a change of activation energy with time may be as a result of the decreasing carbon potential of the carburizer with time.

\section{CONCLUSIONS}

The depth of resulting case and the hardness obtained depends on the factors summarized below

(a) The case depth obtained increase with temperature, time and percentage energizer.

(b) The case hardness increases with the percentage energizer and carburizing time for a given temperature.

(c) For a given temperature and percentage energizer, case depth and hardness increases with time.

(d) For a given percentage energizer and time increase, in temperature increase the case depth and hardness.

(e) For a given time and temperature, increase in percentage energizer increases the case depth and its hardness.

(f) Increase in the percentage of energizer decreases the activation energy for diffusion to occur exponentially.

(g) Increase in time decreases the activation energy for diffusion to occur exponentially.

\section{REFERENCES}

[1] America Society of Metals(1964); Metals Hand book, Heat-treating, cleaning and finishing. $8^{\text {th }}$ ed.

[2] M.A. Majid ad H.C. Child; Effect of carburizing on unidirectional bending fatigue strength of low alloy steel. (1983). Journal of Metals Technology, Vol. 10 page 173.

[3] Lakhtin,Yu.M(1977); Engineering Physical Metallurgy and Heat Treatment. Mir Publishers, 
Moscow.

[4] Smith, W.F(1970); Principles of Materials Science and Engineering. $2^{\text {nd }}$ ed. Mc GrawHill Int. ed.

[5] Simon, E.N(1974); Dictionary of Metal Heat Treatment. Frederic Muller Ltd, London.

[6] Prabhudev K.H (1997) Handbook of Heat treatment of Steels. $4^{\text {th }}$ ed. Tata Mc GrawHill Publishing Company Ltd. New Delhi.

[7] Rajput R.K(2002) Materials Science and Engineering. $2^{\text {nd }}$ ed. S.K.Katara \& Sons, New Delhi.

[8] Degarmo E. Paul, Black J.T \& Kohser A. Ronald(1997) Materials and Processes in Manufacturing. $8^{\text {th }}$ ed. Prentice-Hall of India Private Ltd., New Delhi.

[9] George S.Brady and Henry R. Clauser(1989) Materials Handbook.12 ${ }^{\text {th }}$ ed. Mc Graw-Hill Publishing Company, New York.

[10] Higgins R.A (1983) Engineering Metallurgy Part 1. 